Original Research Paper

\title{
New Approach to Study Stimulating Effect of the Pre-Sowing Barley Seeds Treatment in the Electromagnetic Field
}

\author{
${ }^{1}$ Aliya S. Kasakova, ${ }^{2}$ Igor V. Yudaev, ${ }^{3}$ Michael G. Fedorishchenko, \\ ${ }^{1}$ Svetlana Yu. Mayboroda, ${ }^{3}$ Nikolay V. Ksenz and ${ }^{2}$ Sergey M. Voronin \\ ${ }^{1}$ Department of Agronomy and Crop Breeding, Azov-Black Sea Engineering Institute, \\ Federal State Budgetary Educational Institution of Higher Education, Don State Agricultural University, \\ 347740, 21 Lenin Str., Zernograd, Russian Federation \\ ${ }^{2}$ Department of Thermal Engineering and Information Management System, \\ Azov-Black Sea Engineering Institute, Federal State Budgetary Educational Institution of Higher Education, \\ Don State Agricultural University, 347740, 21 Lenin Str., Zernograd, Russian Federation \\ ${ }^{3}$ Department of Technosphere Safety and Physics, Azov-Black Sea Engineering Institute, Federal State Budgetary Educational \\ Institution of Higher Education, Don State Agricultural University, 347740, 21 Lenin Str., Zernograd, Russian Federation
}

Article history

Received: 15-02-2018

Revised: $17-02-2018$

Accepted: 02-05-2018

Corresponding Author: Igor V. Yudaey

Department of Thermal

Engineering and Information

Management System, Azov-

Black Sea Engineering Institute,

Federal State Budgetary

Educational Institution of Higher

Education Don State

Agricultural University,

347740, 21 Lenin Str.,

Zernograd, Russian Federation

Email: etsh1965@mail.ru

\begin{abstract}
Improvement of the agricultural crops seeds quality with their pre-sowing treatment in the electromagnetic field and the subsequent increase in grain yield and studying the mechanisms of stimulating effects - all those are the important problems of science and practice of the crop-growing sector. The purpose of the presented research was to study the mechanism for increasing the germinating ability of spring barley seeds as a result of pre-sowing treatment with an alternating electromagnetic field of an industrial frequency $(50 \mathrm{~Hz})$ for one second. After four days of storing, treated seeds were germinated under optimal conditions for this process and the number of germinated seeds of two spring barley varieties was counted each day during seven days period. Also we studied the onset, duration and passage of Microphenological Phases of Seeds Germination (MPPSG), based on the observation and the time registration of each seed morphological changes during germination with two-hour periodicity for seven twenty-four hours. It was established that seeds treatment in an electromagnetic field leads to an acceleration of their germination for one day due to the appearance of rapidly germinating seeds fraction and disappearing of the slowest germinating seeds fraction. This is due to the acceleration of the onset of all MPPSGs and reducing of their duration. Despite the reduction in the absolute values of the duration (in hours) of all MPPSGs, two phases ("Swelling" and "Short roots") began to occupy a greater time percentage in the structure of the germination period after seeds pre-sowing treatment. It is interesting, that treated seeds also absorb more water during the swelling period than untreated seeds, although the duration of that period has shortened. Therefore, the conclusion was made about stimulation of accelerated water absorption by seeds during the swelling period, the duration of which is shortened, by the electromagnetic field. It was established that there are fractions in the seed lots of different spring barley varieties that respond differently to treatment. Consequently, when studying the mechanism of the electromagnetic field influence on seeds germination, it is necessary to study not only the total effect, but also take into account the reaction of individual fractions. The proposed experimental approach can be used as an informative tool for obtaining new knowledge in the field of the stimulating effect of seed treatment in an alternating electromagnetic
\end{abstract}


field of the industrial frequency on their germinating ability and further growth and development of plants.

Keywords: Seeds, Barley, Alternating Electromagnetic Field of Industrial Frequency, Germination, Microphenological Phases of Seeds Germination

\section{Introduction}

The study of the electromagnetic field influence on the seeds germination, the growth and development of plants and their subsequent yield is one of the important problems of modern biological science and practical crop-growing production and which attracts the attention of many scientists and therefore numerous studies were devoted to the study of this phenomenon, the results of which are presented in various publications (Kutis and Kutis, 2017; Belyavskaya, 2004). In general, the increase in yields for different types of seed treatments by electrophysical factors is 10 to $30 \%$ with different crops. But at the same time, the mechanism of the phenomena taking place in the internal structures of seeds was not fully established to date. Using the example of different cultures, it was shown that seeds treatment in an electromagnetic field leads to an increase in their germination, an increase in the biomass and linear sizes of seedlings (Menshova and Nizharadze, 2012; Iqbal et al., 2012; Efthimiadou et al., 2014; Rostami et al., 2014; Vashisth and Nagarajan, 2010), improves the absorption of mineral elements from the soil (Kavi, 1977), increases the activity of some enzymes (Racuciu et al., 2006), increases the content of photosynthetic pigments in leaves (Dhawi and Al-Khayri, 2009). Seed treatment in a magnetic field with $3 \mathrm{mT}$ intensity positively affects the cell division rate for $4 \mathrm{~h}$, the synthesis of DNA and RNA and reduces the number of chromosomal aberrations (Shabrangi et al., 2011). The water absorption of seeds reaches its maximum value when treating them in a magnetic field with a strength of 3.5-5.0 kA/m (Popandopulo et al., 2010). The study of the influence of ultrahigh-frequency electromagnetic fields and high tension (Kasakova et al., 1987; Tibirkov and Yudaev, 2015; Yudaev et al., 2016) on the germination and growth energy of cereals and oilseeds in conditions of arid agriculture in the south of Russia showed that there is clearly a positive effect of such treatment both in laboratory and field conditions, which consisted in an earlier and amicable appearance of seedlings, increased growth energy, germination of treated seeds even in conditions of a minimum reserve of moisture and dry soil.

One of the central problems of all such studies is the identification of the mechanism of the electromagnetic fields influence on the process of germination of seeds. Numerous experiments in the laboratory revealed various effects of the electromagnetic fields' influence on biological objects, as a result of which hypotheses were made about the mechanism of their primary action. For example, this was due to phase transitions in the liquid crystal system, biological activation of metastable free water, free radical processes, paramagnetic resonance, etc. (Belyavskaya, 2004). The positive reaction of maize seeds (monocotyledons) and rape plant (dicotyledons) to pre-treatment in an alternating electromagnetic field of $60 \mathrm{~Hz}$ frequency is explained by the fact that the observed positive effect is due to a shortterm increase in temperature and an increase in the energy of biological systems (cells) as a result of the interaction of iron atoms with electromagnetic field in those cells where there is a lot of ferritin (Shabrangi et al., 2011). In experiments on wheat seeds, an alternating electromagnetic field with a frequency of $30-33 \mathrm{~Hz}$ led to an increase and rate in the germination, the absence of mold on the seeds and also to an abrupt change in $\mathrm{pH}$ near the surface of the embryo per unit after 5-6 $\mathrm{h}$ after treatment (Aksenov et al., 1996). In these and several other research to study the physiology and biochemistry of germinating seeds, all seeds that have been processed were selected for testing, although it is known that the seeds are of a different quality not only in mass and linear dimensions, but also in dormancy depth and also in activation rate and activity of metabolic processes during germination.

We proposed improved full scale of Microphenological Stages of barley seed Germination (MPPSG) (Kasakova and Kozyaeva, 2009; Kasakova, 2014), through which it is possible to visually identify the growth dynamics for each individual seed. If we register the morphological changes that occur during the entire period from the soaking of seeds to the formation of a full seedling, then it is possible to determine the time of occurrence of each MPPSG for both the individual seed and for the whole seed lot. In addition, it is possible to determine the duration of each microphage stage, characterize the course of the process in time and also to separate individual fractions of seeds and establish the nature of the response to external influences. However, this methodological approach was not used to study the mechanism of the stimulating effect of the electromagnetic field on the germination of seeds.

Purpose of the research is to reveal the mechanism for increasing the germination and reaction of individual spring barley seed fractions as a result of their pre-sowing treatment with an alternating electric field of an industrial frequency of $50 \mathrm{~Hz}$ on the basis of an analysis of the onset, duration and passage of 
microphenological phases of barley seed germination (Seeds of Agricultural Crops, 2004).

\section{Materials and Methods}

The seeds of two varieties of spring barley of the leading breeding centers in the south of Russia Zernogradsky 584 (I.G. Kalinenko All-Russia Research Institute of Grain Cultures, Zernograd, Rostov-on-Don Region) and Rubicon (P.P. Lukiyanenko Krasnodar Scientific Research Institute of Environmental Protection, Krasnodar) were used as the object of the research. Both varieties are included in the State Register of Selection Achievements of the Russian Federation. Seeds were grown on the fields of the educational and experimental farm of the Azovo-Chernomorsky Engineering Institute to Azov-Black Sea Engineering Institute in the seed field of competitive variety testing according to the technology adopted in the zone.

Seeds were germinated in rolls of filter paper according to GOST-12038-84 under optimal conditions on distilled water at $+20^{\circ} \mathrm{C}$ for 7 days. The energy of seed germination was determined after three and germination - after seven days from sowing.

Dynamics of seed germination were determined by revealing seed fractions differing in germination rate, for which the number of germinated seeds was counted at the same time for each day.

Study of the onset, duration and passage of MPPSG by the seeds. For this, the seeds were germinated in the on filter paper on distilled water at $+20^{\circ} \mathrm{C}$ for seven days according to the state standard (GOST 12038-84). The seeds were neatly laid out in 100 units in germinators in rows and each seed was analyzed: Every seed was examined every two hours for seven days, recorded and registered the time of the onset of a certain MPPSG. Based on the obtained data, the table of the occurrence of each MPPSG for each seed was completed and then the mean values of the onset and duration of the MPPSG were found and a model for changing the number of seeds in each MPPSG during the germination process was constructed. The experiment was taken in triplicate.

The definition of MPPSG was carried out according to their description (Kasakova and Kozyaeva, 2009; Kasakova, 2014). The following MPPSGs, characteristic for healthy barley seeds, was determined: (1) "Dry grain" (DG) - dry dormant seed; (2) "The onset of swelling" (Swelling) - start of seed imbibition (the moment of soaking seeds; (3) "Point" (P) - the emergence of radical covered by coleorhizae and it looks like the white point on the embryo tip of the seed; (4) "Roots 1" (R1, or "Fork") - when one, two or three embryonic roots up to $2 \mathrm{~mm}$ long appear successively through the rupture in the coleorhizae and they resemble a fork in shape; (5) "Short roots" (Roots 2, R2) - radical and seminal roots elongation, but all roots are shorter than the long axes of the seed; (6) "Long roots" (Roots 3, R3) - when at least one or more roots become longer than the long axes of the seed; (7) "Shoot" (Sh) - corresponds to the moment of coleoptile emergence, but coleoptile's length is less than half long axes of the seed, while the length of the shoot is taken into account for the part that went beyond the floral glume; (8) "Seedling" (S) - the formation of a full seedling according to GOST12038-84, when there are two or more roots longer than the long axes of the seed and a shoot with a size not less than half the long axes of the seed with the visible primary leaves occupying not less than half the length of the coleoptile.

Pre-sowing treatment of seeds in an alternating electromagnetic field of an industrial frequency of $50 \mathrm{~Hz}$ was carried out on a laboratory installation, which is a module of the EEO installation consisting of a working chamber, a magnetic circuit and an electromagnetic coil and an automatic control device (Fig. 1). In the working chamber of the advanced module, an alternating electromagnetic field of an industrial frequency of $50 \mathrm{~Hz}$ (AEMF IF) was created, which ensures the induction of 0.03 T-optimal for seed pre-sowing treatment (Fedorishchenko et al., 2009).

The seeds selected for treatment were placed in an installation and processed in an Alternating Electromagnetic Field of an Industrial Frequency of 50 $\mathrm{Hz}$ (AEMF IF) for $1 \mathrm{sec}$. After that, the seeds were left for four days for resting and on the fifth day they were germinated. This treatment regime is most effective for barley seeds, which was proved by laboratory and field experiments (Fedorishchenko et al., 2009).

The moisture content of the seeds found in different MPPSG was determined by the weight method with some modifications. If the germinating seeds are selected by MPPSG from one common sample (for example, from one germinator), then seeds that germinate more slowly will enter each subsequent MPPSG. To avoid such an error, the seeds were laid for germination at the same time in six germinators (according to the number of determined MPPSGs) and then seeds from only one MPPSG were taken from each germinator.

Statistical processing of the results. The results of the studies were subjected to statistical analysis using the MS Excel package. The reliability of the differences of the compared pairs of values was estimated by the Student's t-test at a 5\% significance level. 


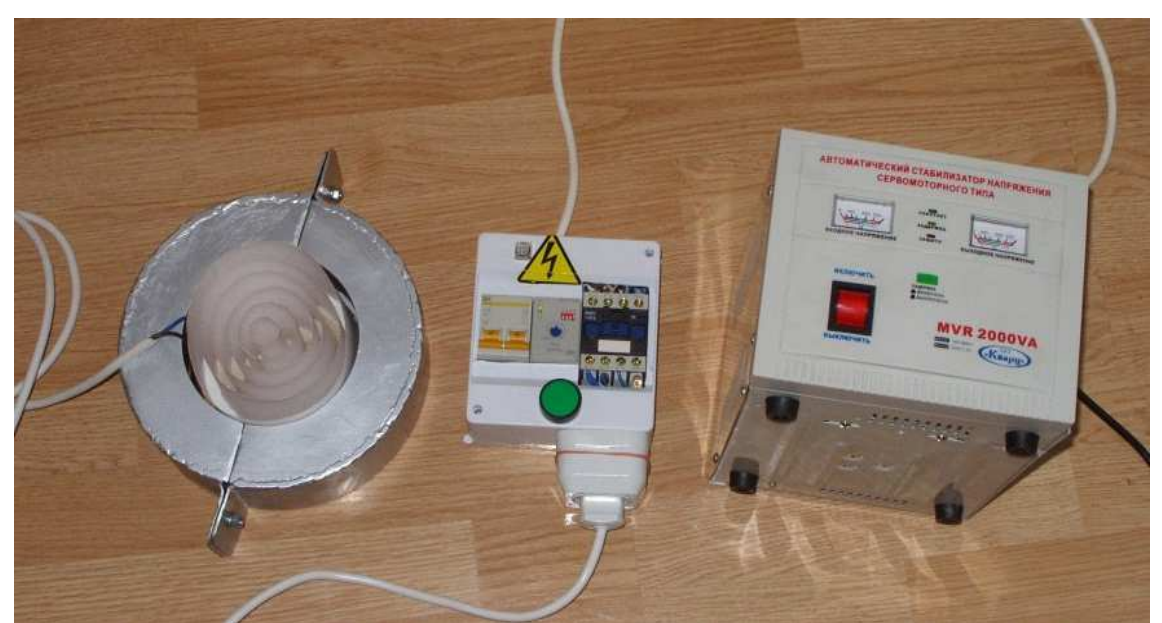

(a)

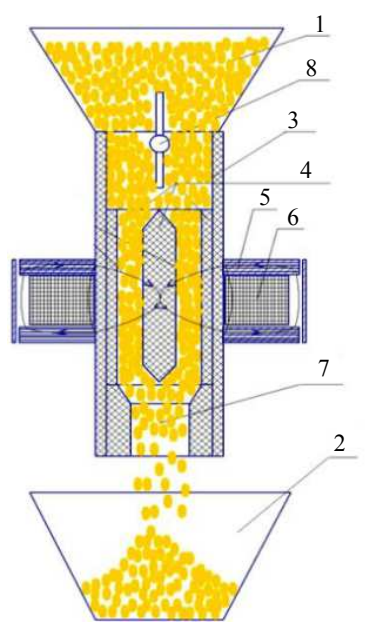

(b)

Fig. 1: Appearance of the laboratory installation for seed treatment with an alternating electromagnetic field of the industrial frequency $(a)$ and the scheme of the EEO installation device $(b): 1$ - bin; 2 - gainer bin; 3 - nonmagnetic material pipe; 4 - nonmagnetic material patch; 5 - square-cut circular pole-pieces; 6 - magnetizing coil; 7 - nonmagnetic material vignetter; 8 - apron

\section{Results}

Germination of seeds. Pre-sowing treatment of seeds with high initial germination results in its insignificant increase - by $4 \%$ in both varieties, all the while significantly increasing the germination energy: by 36 and $42 \%$ in seeds of Zernogradsky 584 and Rubicon, respectively (Table 1).

Since the germination energy reflects the number of seeds germinating over three days, an increase in the number of such seeds can have a positive effect on obtaining amicable shoots in the field, the planned plant stand and, ultimately, will positively affect yields. Therefore, the research interest is to perform more detailed study of the effect of seed treatment in the alternating electromagnetic field of the industrial frequency on certain characteristics of their germination process.

Dynamics of barley seeds germination were studied, determining the number of germinated seeds for each day (Table 2).

In the control, all germinal seeds of the Zernogradsky 584 variety geminated for 6 days and Rubicon variety - for 5 days, with the main amount of germinated seeds observed in three and four days. Seed treatment in the alternating electromagnetic field of the industrial frequency as a whole leads to an acceleration of seeds germination and reduces the entire germination period in both varieties for one day due to the appearance of a fraction of rapidly germinating (after 2 days) and the disappearance of the fraction of the slowest germinating (for the 5th and for the 6th day) of the seeds. In the field, this effect of pre-sowing seeds treatment on the germination leads to an increase in field germination and the formation of more powerful seedlings.
However, the acceleration of germination for one day does not occur by simply moving the seeds from one fraction to the other. If we count the number of germinated seeds in the control and in the experiment and compare the change in their number by the day, it becomes obvious that the acceleration of seed germination of all fractions occurs only for one day, that is, the seeds cannot "jump" through the fraction and germinate two days earlier. In addition, all seeds react differently to treatment in an alternating electromagnetic field of the industrial frequency. For example, after treatment, only half of the Rubicon variety seeds germinating for 3 days passes into the rapidly germinating fraction (the 2nd day), but the seeds of the fraction of 4 days almost completely pass into a fraction of 3 days. The seeds of the 5-day fraction completely pass into a fraction of 4 days. A similar regularity is also evident in the seeds of the Zernogradsky 584 variety. Consequently, the greatest positive effect of pre-sowing seed treatment in an alternating electromagnetic field of the industrial frequency affects the lagging seeds by accelerating their germination.

The onset and duration of the MPPSG. Based on the data of the round-the-clock, with an interval of two hours, analysis of the morphological changes of each germinating seed, the mean time for the entire seed lot and the duration of each MPPSG were calculated. The obtained values of the studied parameters have significant differences. Table 3 presents the results of a statistical analysis of the results.

Differences in the timing of the onset of each MPPSG are statistically significant, since there is a significant difference between the two mean values (control $\div$ AEMF IF) for the difference criterion: for all compared pairs of values $t_{\text {able }}<t_{f a c t}$. 
Table 1: Change in germination and germination energy of spring barley seeds under the influence of pre-sowing treatment by an electromagnetic field of industrial frequency: $\mathrm{C}$ - control (seeds without treatment); AEMF IF - the seeds are processed in an electromagnetic field of an industrial frequency of $50 \mathrm{~Hz}$ for one second

\begin{tabular}{|c|c|c|c|c|c|c|}
\hline \multirow[b]{2}{*}{ Variety } & \multicolumn{3}{|c|}{ Germination energy, $\%$} & \multicolumn{3}{|c|}{ Germination, $\%$} \\
\hline & $\mathrm{C}$ & AEMF IF & \pm of C & $\mathrm{C}$ & AEMF IF & \pm of $\mathrm{C}$ \\
\hline Zernogradsky 584 & 52 & 88 & 36 & 94 & 98 & 4 \\
\hline Rubicon & 52 & 94 & 42 & 92 & 96 & 4 \\
\hline
\end{tabular}

Table 2: Effect of pre-sowing seed treatment of two spring barley varieties in an alternating electromagnetic field of industrial frequency on the number of germinated seeds for each day during 7-day germination period

\begin{tabular}{|c|c|c|c|c|c|c|c|}
\hline \multirow[b]{2}{*}{ Breed } & \multirow{2}{*}{$\begin{array}{l}\text { Experiment } \\
\text { variant }\end{array}$} & \multicolumn{6}{|c|}{ Number of germinated seeds ( $\%$ of germination) } \\
\hline & & After 2 days & After 3d day & After 4th day & After 5th day & After 6th day & After 7 th day \\
\hline \multirow[t]{2}{*}{ Zernogradsky 584} & Control & 0 & 52 & 44 & 2 & 2 & 0 \\
\hline & AEMF IF & 17 & 71 & 10 & 2 & 0 & 0 \\
\hline \multirow[t]{2}{*}{ Rubicon } & Control & 0 & 52 & 46 & 2 & 0 & 0 \\
\hline & AEMF IF & 26 & 68 & 6 & 0 & 0 & 0 \\
\hline \multirow[t]{2}{*}{ Average } & Control & 0 & 52 & 45 & 2 & 1 & 0 \\
\hline & AEMF IF & 21 & 70 & 8 & 1 & 0 & 0 \\
\hline
\end{tabular}

Table 3: Results of a pair wise evaluation for each MPPSG of two varieties of spring barley (control $\div$ treatment by the AEMF IF) of the significance of the difference in the occurrence and duration of the t-test (value $t_{\text {table }}=1.96$ )

\begin{tabular}{|c|c|c|c|c|}
\hline \multirow[b]{3}{*}{ MSGS } & \multicolumn{4}{|l|}{ t-test } \\
\hline & \multicolumn{2}{|c|}{ Rubicon } & \multicolumn{2}{|c|}{ Zernogradsky 584} \\
\hline & Onset & Duration & Onset & Duration \\
\hline Swelling & - & 3,68 & - & 2,65 \\
\hline Point & 3,68 & 9,02 & 2,65 & 7,5 \\
\hline $\mathrm{R} 1$ & 10,9 & 8,54 & 3,77 & 3,2 \\
\hline $\mathrm{R} 2$ & 9,48 & 1,52 & 5,36 & 0,34 \\
\hline R3 & 8,82 & 4,26 & 4,31 & 2,43 \\
\hline Shoot & 9,40 & 6,92 & 4,97 & 4,18 \\
\hline Seedling & 11,66 & 13,91 & 5,23 & 6,33 \\
\hline
\end{tabular}

Differences in the duration of each MPPSG in the control and in the experiment are also statistically significant (except for MPPSG R2), since there is a significant difference between the mean values (control $\div$ AEMF IF) by the criterion of the significance of the difference: for the compared pairs of values, the following inequality holds: $t_{\text {able }}<t_{\text {fact }}$.

The timing of the onset of individual MPPSG in control in both studied barley varieties has close values with a difference of 2-4 h (Fig. 2). On average, all seeds of both varieties come to the MPPSG "Point" in 22-24 h and germinate, which is fixed in experiments and was noted for the formation of a full seedling, for 72.8-72.9 h.

Seed treatment in an alternating electromagnetic field of the industrial frequency leads to acceleration of the onset of all MPPSG, but there are varietal differences: In seeds of Rubicon variety, the beginning of all MPPSG occurs earlier, with an average germination time of all seeds less by $6.5 \mathrm{~h}$ than in Zernogradsky 584. The data obtained in this experiment are consistent with the results of studying the dynamics of germination of seeds by day (Table 2 ).

The duration of all MPPSGs of the control lot of seeds differs significantly from 6.9 to $23.5 \mathrm{~h}$ and from 6.7 to $22.2 \mathrm{~h}$ for Zernogradsky 584 and Rubicon varieties, respectively (Fig. 3). The most prolonged MPPSGs are "Swelling" and "Long roots" (R3) and the fastest are the phases "Point" (emergence of radical covered by coleorhizae) and "Shoot" (coleoptile appearance). The order of the location of MSGS for the duration of control seeds germination is the same for both varieties and can be displayed as a series: Swelling $>$ R3 $>$ R2 $>$ R1 $>$ Point $>$ Shoot.

Treatment of dry seeds in an alternating electromagnetic field of industrial frequency leads to a decrease in the duration of all MPPSG germination, except for MSGS "Short roots" (R2). At the same time, it should be noted that the reduction in duration varies from MPPSG to MPPSG. 


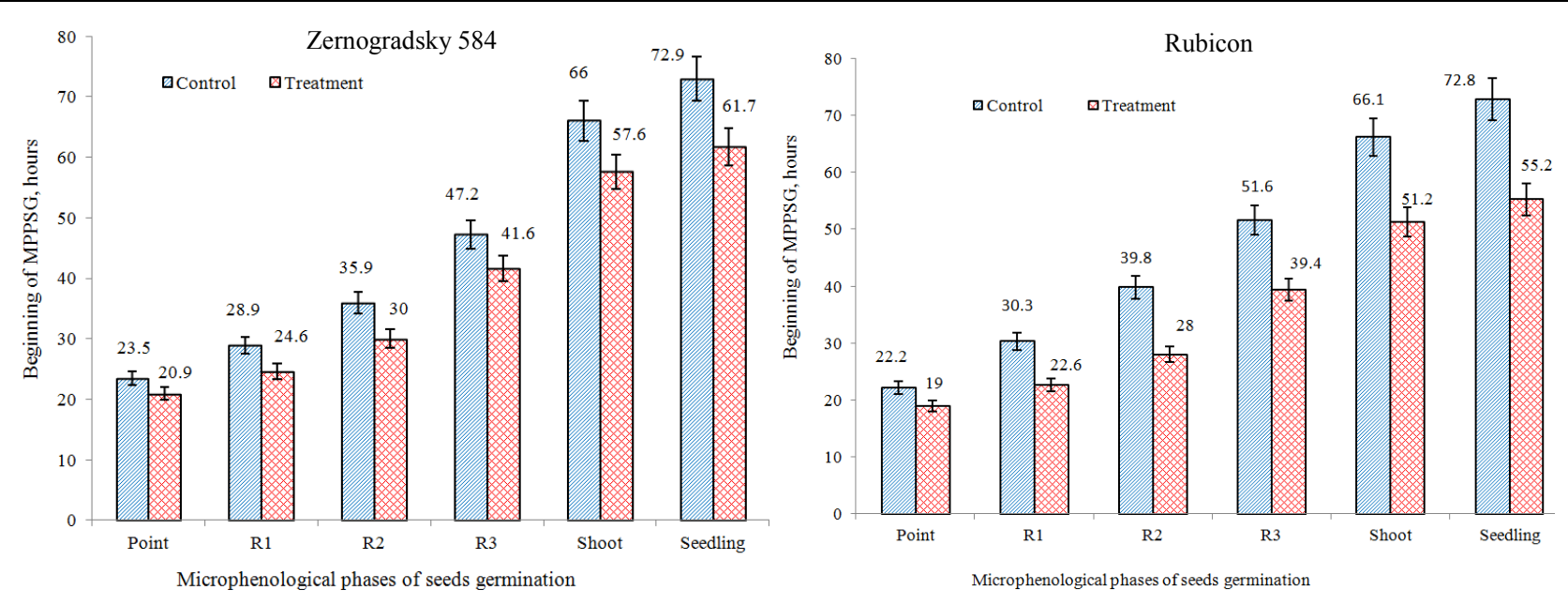

Fig. 2: Influence of pre-sowing seed treatment of two spring barley varieties with an alternating electromagnetic field of the industrial frequency for the time of MPPSG onset during germination under optimal conditions
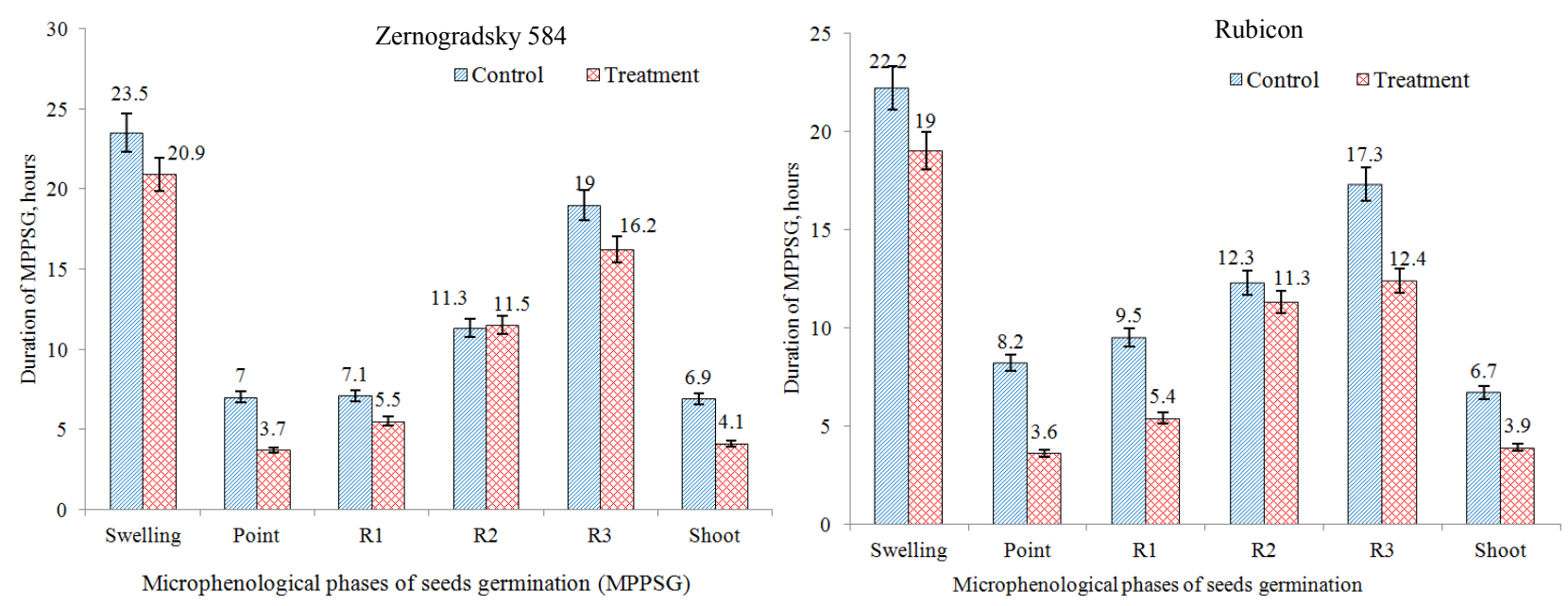

Fig. 3: Influence of pre-sowing seed treatment of two spring barley varieties with an alternating electromagnetic field of the industrial frequency for the time of MPPSG duration during germination under optimal conditions

The order of the location of MPPSG for the duration of germination of the treated seeds is the same for both breeds and can be displayed as a series: Swelling $>$ R $3>R 2>R 1>$ Shoot $>$ Point. Seed treatment results in a change and the greatest reduction in the duration of MPPSG "Point", as for the control seeds, MPPSG "Shoot" was the fastest one.

Seed treatment in an alternating electromagnetic field of industrial frequency leads to a different change in the rate of flow of physiological and biochemical processes on each MPPSG. If the treatment of seeds accelerated only the absorption of water during the swelling period and all other processes would proceed in a stable regime, then the shift in the onset and duration of all subsequent MPPSG should have the same values. However, in practice, there are serious differences, especially in the duration MPPSG (Table 4).
On average, for all MPPSGs, their beginning is accelerated by 16.4 and $23.3 \%$ and the duration by 30 and $32 \%$ for Zernogradsky 584 and Rubicon breeds, respectively. It can be assumed that a significant reduction in the duration of MSGS "Point" and "Sprout" occurred due to the implementation of some metabolic processes in the previous phases - "Swelling" and R3("Long roots") - the duration of which decreased much less. The duration of MPPSG R2 ("Short roots"), when the growth of embryonic rootlets begins, practically does not change, which indicates the independence of these processes from external influences.

Change in humidity of germinating seeds. Seed treatment in an alternating electromagnetic field of industrial frequency influences the onset and duration of MPPSG, primarily affecting the absorption of water by the seeds, so the moisture content of the seeds in different MPPSG was determined (Table 5). 
Pre-sowing seeds treatment in an alternating electromagnetic field of industrial frequency leads to a certain increase in the moisture content of the seeds for all MPPSGs (Table 5). However, according to the criterion of the essentiality of the difference, the humidity after seed treatment significantly increased only when they reached the MPPSG "Point" and "Fork" (R1): For these compared pairs of values (control $\div$ EMF IF) an average of two grades is satisfied: $t_{\text {able }}<t_{\text {fact }}$ (Table 6).

It turned out that with a decrease in the absolute values of the duration (in hours) of all MPPSG (Fig. 3 and Table 4), the phases "Swelling" and "Short roots" (R2) on average on two studied breeds after pre-sowing treatment began to occupy a larger percentage of time in the structure of the sprouting period: By 3.8 and $3.6 \%$, respectively. In this case, the seeds for the decreased swelling after the treatment reach a higher humidity in the MPPSG "Point". This phenomenon, paradoxical at first glance, allows us to consider the mechanism of the stimulating effect of pre-sowing seed treatment in an alternating electromagnetic field of the industrial frequency in the initial stages of plant growth and development.

Passage of MPPSG by seeds. To reveal the mechanism of the effect of seed treatment in the alternating electromagnetic field of industrial frequency on the passage of MPPSGs in time, we studied the change in the number of seeds in the MPPSG "Point" and "Sprout" (Fig. 4). These MPPSG were selected due to the fact that the most significant reduction in their duration after seed treatment is by $40-56 \%$ (Table 4 ).

After the swelling ends, the radical appears (MPPSG "Point") and the number of seeds in this MPPSG first increases, reaches the maximum value and then decreases, as the seeds go into the next phase (MPPSG R1) (Fig. 5). The change in the number of seeds in a particular MPPSGs, shown in the graph, makes it possible to study the features of this process in time.

Table 4: Acceleration of the onset and shortening of the MPPSG duration of two spring barley varieties under the influence of presowing treatment in an alternating electromagnetic field of the industrial frequency

\begin{tabular}{|c|c|c|c|c|}
\hline \multirow[b]{2}{*}{ MSGS } & \multicolumn{2}{|c|}{ Reducing onset time of MPPSG } & \multicolumn{2}{|c|}{ Reducing the duration of MPPSG } \\
\hline & Hours & $\%$ of control & Hours & $\%$ of control \\
\hline \multicolumn{5}{|l|}{ Zernogradsky 584} \\
\hline Swelling & - & - & 2,6 & 11,1 \\
\hline Point & 2,6 & 11,1 & 3,3 & 47,1 \\
\hline $\mathrm{R} 1$ & 4,3 & 14,9 & 1,6 & 22,5 \\
\hline $\mathrm{R} 2$ & 5,9 & 16,4 & 0,2 & 1,7 \\
\hline R3 & 5,6 & 11,9 & 2,8 & 14,7 \\
\hline Shoot & 8,4 & 12,7 & 2,8 & 40,6 \\
\hline Seedling & 11,2 & 15,4 & - & - \\
\hline Swelling $\div$ Seedling & - & - & 13,3 & 17,7 \\
\hline \multicolumn{5}{|l|}{ Rubicon } \\
\hline Swelling & - & - & 3,2 & 14,4 \\
\hline Point & 3,2 & 14,4 & 4,6 & 56,1 \\
\hline R1 & 7,7 & 25,4 & 4,1 & 43,2 \\
\hline $\mathrm{R} 2$ & 11,8 & 29,6 & 1 & 8,1 \\
\hline R3 & 12,2 & 23,6 & 4,9 & 28,3 \\
\hline Shoot & 14,9 & 22,5 & 2,8 & 41,8 \\
\hline Seedling & 17,6 & 24,2 & - & - \\
\hline Swelling $\div$ Seedling & - & - & 20,6 & 27,0 \\
\hline
\end{tabular}

Table 5: Humidity of seeds of two spring barley varieties by MPPSGSs: control - seeds without treatment; AEMF IF - seeds treated in an alternating electromagnetic field of the industrial frequency

\begin{tabular}{|c|c|c|c|c|}
\hline \multirow[b]{2}{*}{ MSGS } & \multicolumn{2}{|c|}{ Zernogradsky 584} & \multicolumn{2}{|l|}{ Rubicon } \\
\hline & Control & AEMF IF & Control & AEMF IF \\
\hline Point & 40,3 & 41,4 & 39,9 & 41,7 \\
\hline Roots1 & 41,5 & 42,6 & 42,3 & 43,6 \\
\hline Roots 2 & 44,0 & 44,1 & 45,4 & 45,9 \\
\hline Roots 3 & 47,8 & 48,8 & 53,4 & 54,2 \\
\hline Shoot & 61,8 & 61,9 & 61,9 & 62,2 \\
\hline Seedling & 62,0 & 63,1 & 62,4 & 63,8 \\
\hline
\end{tabular}


Table 6: Results of a pairwise evaluation (control $\div$ PEMP) of the significance of the difference in the mean for two types of seed moisture according to MSGS according to the t-criterion: $t_{\text {table }}=2.14$

\begin{tabular}{lllllll}
\hline MPPSG & $\mathrm{P}$ & $\mathrm{R} 1$ & $\mathrm{R} 2$ & $\mathrm{R} 3$ & $\mathrm{~S}$ & \\
\hline$t_{\text {факт }}$ & 2,25 & 3,0 & 0,1 & 1,1 & 0,7 & \\
\hline
\end{tabular}

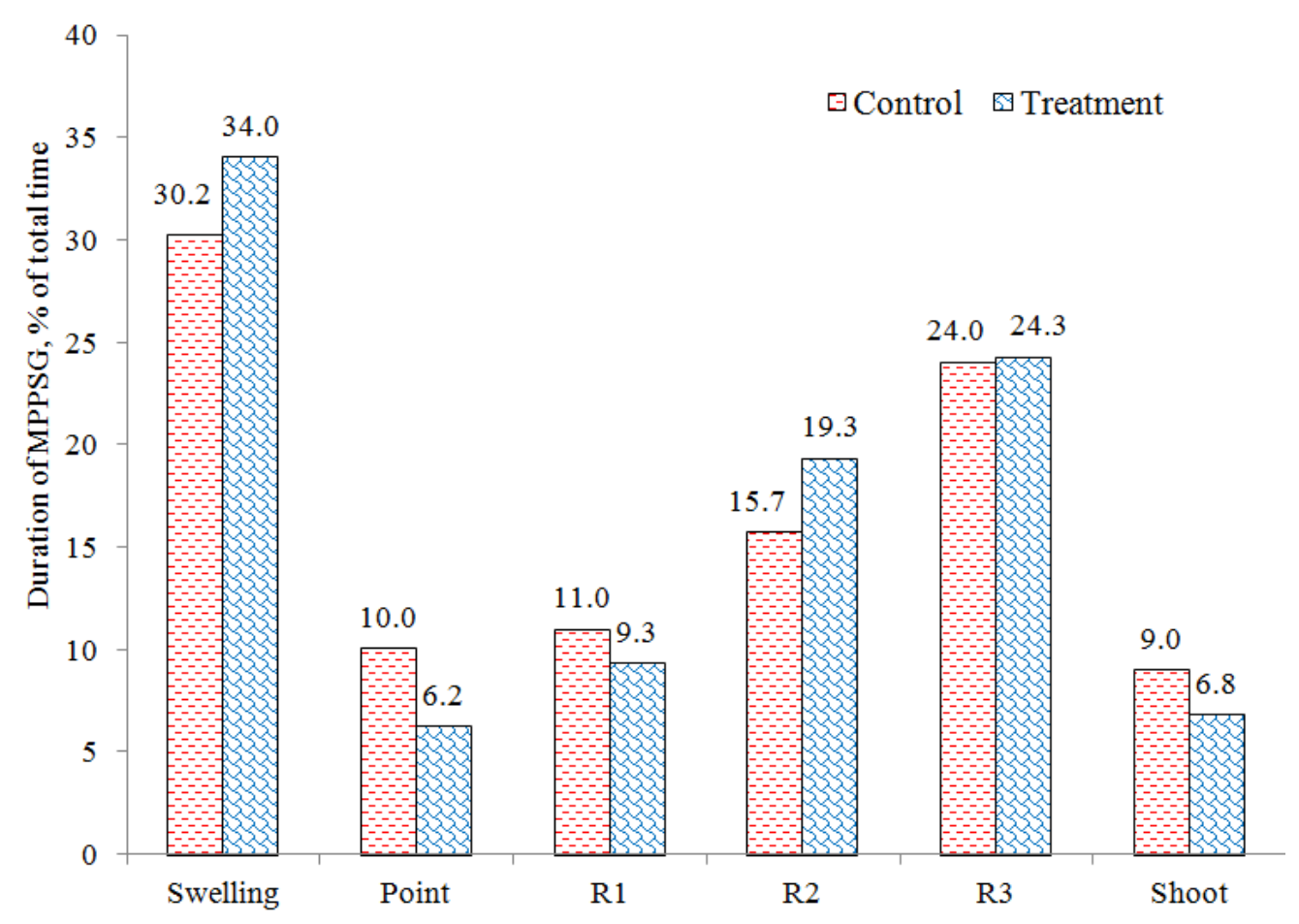

Microphenological phases of seeds germination

Fig. 4: The duration of each Microphage Phase of Germination of Seeds (MPPSG) of spring barley as a percentage of the total germination time from the moment of seed soaking to the formation of a full seedling. Average values for two varieties of spring barley
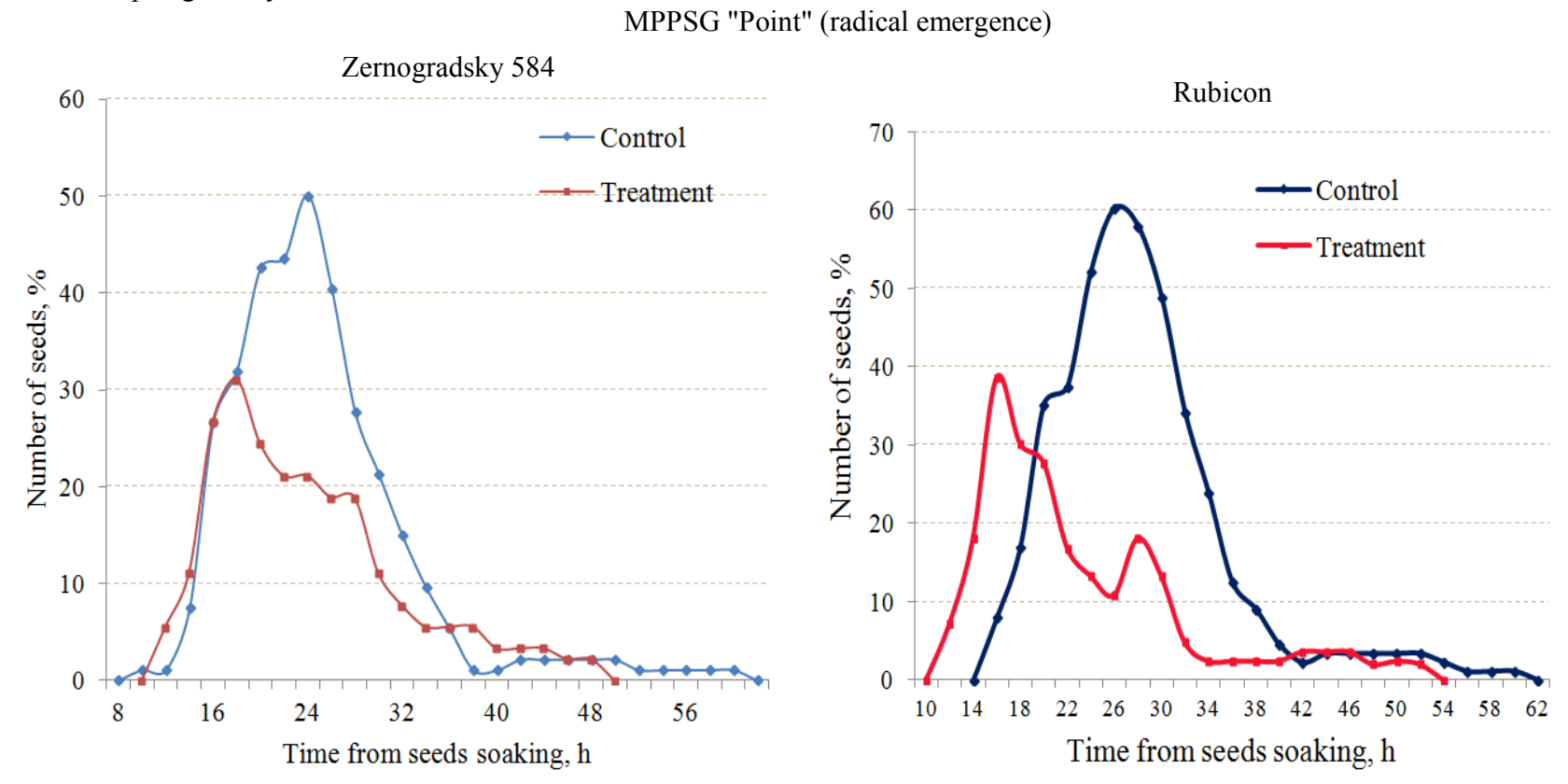

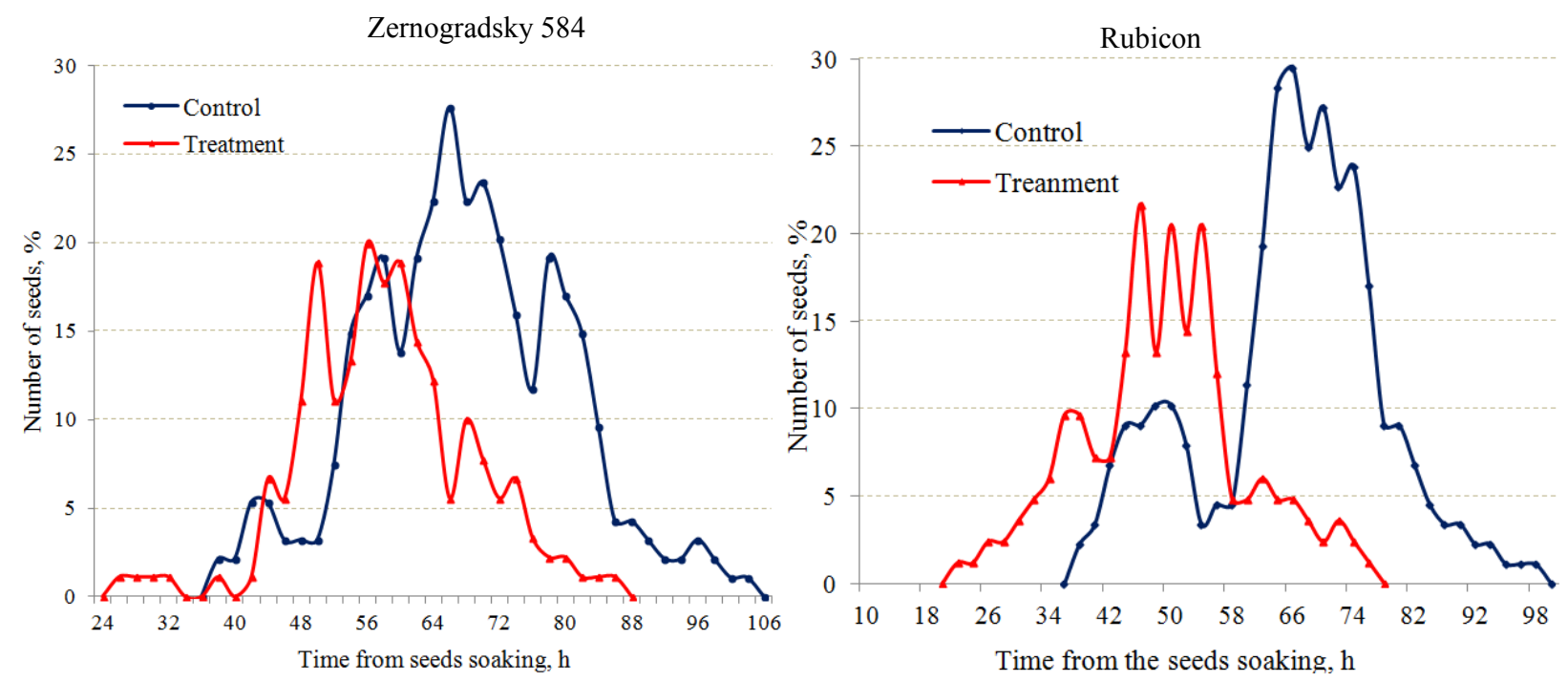

Fig. 5: Passing by spring barley seeds of the microphenological phases of their germination "Point" and "Shoot" under optimal conditions: control - seeds without treatment, treatment - seeds are processed in alternating electromagnetic field of the industrial frequency $1 \mathrm{sec}$

The curves in the graph (Fig. 5) of the number of control seeds in the MPPSG "Point" of both varieties have a single-vertex form and slightly differ from the correct ones. The maximum of the curves is $24 \mathrm{~h}$ for the seeds of the Zernogradsky 584 breed and $28 \mathrm{~h}$ for the seeds of the Rubicon variety. The shape of the distribution curves of seeds indicates their different quality in terms of the ability to rapidly absorb water and germinate: the shoulder on the curves of both breeds in the region of 18-22 $\mathrm{h}$ of germination is associated with the presence of a fraction of rapidly germinating seeds. The presence of right-hand "tails" on the curves indicates that there is an insignificant amount of very slowly germinating seeds that can be in the MPPSG "Point" for a long time.

Seed treatment in the alternating electromagnetic field of the industrial frequency in both varieties accelerates the transfer of seeds to the MPPSG "Point", while the maximum value on the curve decreases by $20 \%$ and the main maximum shifts toward lower values by 8 and $12 \mathrm{~h}$ for Zernogradsky 584 and Rubicon breeds, respectively. The shape of the curve on the chart becomes multi-peak, which indicates the presence of several fractions of seeds, which react differently to treatment.

The curves of MPPSG "Shoot" seeds as a whole reflect the same trend as the passing of MPPSG "Point". Seed treatment in the alternating electromagnetic field of the industrial frequency speeds up their transition to this MPPSG at 12 and $16 \mathrm{~h}$ for the Zernogradsky 584 and Rubicon breeds, respectively and the curve in the chart shifts to a lower range. But there are also differences: the curves of the control and treated seeds are of a broken nature, which is associated with the rapid transfer of seeds to MPPSG "Shoot", that is, with the formation of the seedling formed and the nonsimultaneous passage of this MPPSG in the seeds of different fractions. At the same time, there are no righthanded "tails" on the charts of control and treated seeds. This may be due to the fact that the delay in germination of seeds is observed at early stages during swelling, MPPSG "Point" and transition to active growth - and then the rate of growth processes becomes the same for seeds of a certain grade.

\section{Discussion}

Current approaches to studying the mechanisms of the stimulating effect of magnetic and electric fields are based on the study of the total effects of seed treatment, namely on the determination of germination energy, germination and yield. The method proposed by us, based on the study of the morphological changes of each seed in the process of germination in the period from soaking to the stage of a full seedling, allows a more detailed assessment of the passage by the seeds of individual phases of germination and the influence of pre-sowing treatments on them.

It turned out that seeds of the same seed lot react differently to pre-sowing treatment with an electromagnetic field of industrial frequency. For example, seeds that germinate within three days only partially pass into a fraction germinating in two days and seeds germinating in four and five days are wholly converted into a fraction of more "fast" seeds (Table 2). It is interesting that the presence of different fractions is preserved in the treated seeds before the formation of a full seedling (Fig. 5). The 
study of physiology and biochemistry of seed germination of various fractions in the control and after treatment will help to reveal the mechanism of the stimulating effect of the electromagnetic field.

The reduction in the period of swelling of barley seeds in our experiments after their treatment with an electromagnetic field of 11 and $14 \%$ by varieties (Table 4) is simultaneously accompanied by an increase in the seeds moisture content of the MPPSG "Point" by 1.7 and $1.8 \%$ (Table 5). Previously, it was shown that at the tip of the radical of swelling barley seeds, an increase in humidity is accompanied by a decrease in the ABA content after $5 \mathrm{~h}$ from the beginning of swelling and cell division begins 4-6 $\mathrm{h}$ before the appearance of coleorhizae. The appearance of the radical occurs simultaneously with the activation of a number of genes that regulate cell division (Gendreau, 2008). Also it was found that the germination rate of the lettuce seeds linearly depends on the increase in the turgor of the embryo cells (Bradford, 1990). Thus, the hydration of seed embryo tissues plays a regulating role in the initiation of germination processes. Apparently, pre-sowing stimulation of seeds with an electromagnetic field leads, first of all, to accelerated absorption of water by seeds, which may be due to the state of the water channels or the increase in the absorbing power of the seed embryo cells.

Acceleration of the course of MPPSG "Point" (the appearance of the radical) in the seeds treated with an electromagnetic field, on average, is $51.5 \%$. This indicates a significant acceleration of physiological and biochemical processes already during the swelling of seeds. Thus, according to gene expression data in germinating seeds of Arabidopsis, a transcript interaction model (SeedNet) was developed in which the domains of dormant and seed germination genes are represented, as well as an intermediate region of transcripts, including genes that are responsible for the transition of cells from one phase to another (Bassel, 2011). It can be assumed that the treatment of seeds in the electromagnetic field primarily activates the expression of genes, whose activity products accelerate the cell division in the tissues of the seed embryo.

\section{Conclusion}

On the basis of the experimental data obtained, it can be concluded that pre-sowing treatment of spring barley seeds in an alternating electromagnetic field of industrial frequency has the following effects:

- Accelerates the germination of the entire seed lot for one day

- Has the most stimulating effect on slowly germinating seeds

- Has a different stimulating effect on the seeds of the same lot and even one fraction: for example, seeds germinating in control for three days after treatment in an alternating electromagnetic field of industrial frequency only partially pass into a fraction of seeds germinating in two days

- Reliably accelerates the occurrence of each regular MPPSG by 11.1-16.4\% for barley seeds of Zernogradsky 584 variety and $14.4-29.6 \%$ for Rubicon seeds

- Reliably reduces the duration of seed stay in all MPPSGs, except phase R2 ("Short root"), while the duration of MPPSGs "Point" and "Shoot" is reduced by $40-56 \%$

- Changes the ratio (in percentage of the whole germination period) of the duration of individual MPPSG, increasing the proportion of phases "Point" and R2 ("Short roots")

- Reliably increases the humidity of seeds in MPPSG "Point" and R1

- Changes the passage by seeds of MPPSG "Point" and "Shoot", while the value of the maximum of the curves decreases and shifts to a smaller range, the presence of seed fractions that react differently to the treatment clearly manifests itself

Thus, the pre-sowing treatment of spring barley seeds in an alternating electromagnetic field of industrial frequency shortens the seed swelling period, but simultaneously leads to the achievement of a higher humidity during this time, which may be associated with an increase in the suction power of the seeds. At the same time, in the structure of the germination period from the moment of seed soaking to the formation of the seedling, the duration of MPPSG "Swelling" is reduced by $11-14 \%$ and the next MSGS "Point" - by $47-56 \%$. So, the reaction of seeds of the same seed lot to the treatment manifests itself in varying degrees.

The study of the primary stages of seeds water uptake and the sequence of their passing through the microphenological phases of germination can be used as an experimental approach for studying the reaction of seeds to environmental influences and also will help to decode the mechanisms of dormant seeds reaction for short-term treatment with an alternating electromagnetic field of the industrial frequency.

\section{Author's Contributions}

Aliya S. Kasakova: Designed the research plan, contributed to the writing of the manuscript and organized the study.

Igor V. Yudaev: Supervised the study, coordinated the data-analysis and revised the manuscript.

Michael G. Fedorishchenko: Designed the study, conduct data analysis and manuscript preparation.

Svetlana Y. Mayboroda: Contribution of data and Interpretation of data. 
Nikolay V. Ksenz: Coordinated the data-analysis and contributed to the writing of the manuscript.

Sergey M. Voronin: Gave suggestions and drew conclusions.

\section{Ethics}

This article is original and contains unpublished material. The corresponding author confirms that all of other authors have read and approved the manuscript and no ethical issues involved.

\section{References}

Aksenov, S.I., A.A. Bulychev, B.N. Grunina and B.B. Turovetsky, 1996. On the mechanisms of the effect of a low-frequency magnetic field on the initial stages of wheat germination. Biophysics, 41: 919-924.

Bassel, G.W., H. Lan, T. Glaab, D.J. Gibbs and T. Gerjets et al., 2011. Genome-wide network model capturing seed germination reveals coordinated regulation of plant cellular phase transitions. Proc. National Acad. Sci. USA, 23: 9709-9714.

Belyavskaya, N.A., 2004. Biological effects due to weak magnetic field on plants. Adv. Space Res., 34: 1566-1574.

Bradford, K.J., 1990. A water relation analysis of seed germination rate. Plant Physiol., 2: 840-849.

Dhawi F. and J.M. Al-Khayri, 2009. Magnetic fields induce changes in photosynthetic pigments content in date palm (Phoenix dactylifera L.) seedlings. The Open Agriculture Journal, 3: 1-5.

Efthimiadou A., N. Katsenios, A. Karkanis, P. Papastylianou and V. Triantafyllidis, I. et al., 2014. Effects of Presowing Pulsed Electromagnetic Treatment of Tomato Seed on Growth, Yield, and Lycopene Content. The Scientific World Journal,2014:369745. DOI: 10.1155/2014/369745

Fedorishchenko, M.G., A.S. Kasakova, N.I. Shabanov and M.V. Zholobova, 2009. Effect of the duration of the pre-sowing treatment of barley seeds with an alternating magnetic field of the industrial frequency on the germination, depending on their initial moisture content. Bull. Agrarian Sci. Don, 1: 38-42.

Gendreau, E., S. Romaniello, S. Barad, J. Leymarie and R. Benech-Arnold et al., 2008. Regulation of cell cycle activity in the embryo of barley seeds during germination as related to grain hydration. J. Experimental Botany, 2: 203-212.

Iqbal M., D. Muhammad, Y. Jamil andM.R. Ahmad, 2012. Effect of pre-sowing magnetic field treatment to garden pea (Pisumsativum L.) seed on germination and seedling growth. Pakistan J. Botany, 44: 1851-1856.
Kasakova, A.S. and S.Y. Kozyaeva, 2009. Scale of microphenological phases of germination of spring barley seeds. Agric. Biol., 3: 88-92.

Kasakova, A.S., 2014. Microphenological phases of barley seed germination: Description, time of start and duration. Science of Krasnoyarsk, 17: 139-154.

Kasakova, A.S., B.N. Malinovsky, E.I. Lipkovich, Y.V. Ionova and V.I. Pakhomov, 1987. Influence of ultrahigh frequency electromagnetic field processing on the sowing qualities of sorghum, sunflower and corn seeds. Reports Acad. Agric. Sci., 11: 72-79.

Kavi P.S., 1977. The effect ofmagnetic treatment of soybean seed on itsmoisture absorbing capacity. Science and Culture, 43: 405-406.

Kutis, S.D. and T.L. Kutis, 2017. Electromagnetic technologies in plant growing. Part I. Electromagnetic treatment of seeds and planting stock. Publishing Solutions.

Menshova, Y.A. and S. Nizharadze, 2012. Seed treatment by electromagnetic field of EHF-range by pulsed magnetic field with the aim of increasing yield and protection against diseases. Bull. Samara Center Russian Acad. Sci., 14: 241-244.

Popandopulo, K.K., N.V. Ksenz, I.G. Sidortsov and B.N. Sorokin, 2010. The mechanism of increasing the water absorption of seeds under the influence of a magnetic field. Bull. Agrarian Sci. Don, 1: 10-15.

Racuciu M., D. Creanga and C. Amoraritei, 2006. Biochemical Changes Induced by Low Frequency Magnetic Field Exposure of Vegetal Organisms. Romanian Journal of Physics, 5-7: 645-651.

Rostami Z.E., A. Majd and S. Arbabian, 2014. Effects Of Electromagnetic Fields On Seed Germination In UrticaDioica L. Int. J. Scientific \& Technology Res, 4: 365-368.

Seeds of Agricultural Crops, 2004. Methods for determination of germination: GOST 12038-84; Implemented on 01.07.86. IPK Publishing Standards, Moscow.

Shabrangi A., A. Majd and M. Sheidai, 2011. Effects of extremely low frequency electromagnetic fields on growth, cytogenetic, protein content and antioxidant system of Zea mays L. Afr. J. Biotechnol., 10: 9362-9369.

Tibirkov, A.P. and I.V. Yudaev, 2015. Electrophysical treatment of seeds - a new agroprocess for the cultivation of spring barley in the south of Russia. Fundamental Res., 2: 4930-4933.

Vashisth A. and Sh. Nagarajan, 2010. Effect on Germination and Early Growth Characteristics in Sunflower (Helianthus annuus L.) Seeds Exposed to Static Magnetic Field. Jornal of Plant Physiology, 167: 149-156.

Yudaev, I.V., M.P. Aksenov and N.Y. Petrov, 2016. Results of studies of stimulation of sunflower seeds of NK Neoma by electromagnetic field and Zerebra Agro growth regulator. Herald Agrarian Industrial Complex Stavropol, 1: 153-158. 